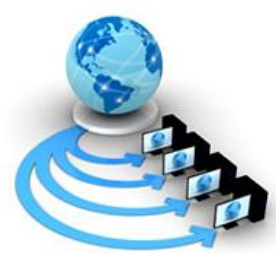

\title{
IMPROVED PERFORMANCE MANAGEMENT INFORMATION SYSTEM FOR BUSINESS ORGANIZATION
}

\author{
$\mathrm{N}$-aabe Kpigigbue \\ ICTC \\ Rivers State University \\ Port Harcourt, Nigeria
}

\author{
Ledisi G. Kabari \\ Computer Science Department \\ Ken Saro-Wiwa Polytechnic \\ Bori, Nigeria
}

\begin{abstract}
Most of the business organization, firms, institutions parastatals today fail in the actualization of their aim and objectives due to inadequate of a standard management information system that will ensure efficient decision-making process. The paper presents an improved information management system for business organization that will monitor and evaluate staff/workers of business organization with the view of ensuring accurate, timely information management system that is geared towards effective performance and decision-making process which will serves as a base for assessing the staff or workers for promotion, pension and rewards or benefits. The system utilized biometric features like fingerprints as an input which is a means for identifying who have access to the system. The methodology implored is the object oriented (OO) methodology and design, the system will be implemented using C-Sharp Programming language.
\end{abstract}

Keywords: Business Organisation; Management; Monitor; Performance; Productivity; Reward

\section{INTRODUCTION}

Looking at institution, firms, ministries and department in the advance financial system of North America, Japan and Western Europe which placed very powerful importance on performance management system in respect to workers [1]. There is business competitiveness among members state on how to grow its financial method all over the globe for several reasons. Performance management is growing powerful in the public sector. Today, there are methods and ways of controlling of public wealth and the call for the need for competence and productiveness in civil service delivery. The plan now turns into a rightful execution operation to deliver eminence jobs done in a changing and various civil service/sector area/environment [2]. The bliss of civil service redesign that begins in Anglo Saxon countries during the late 1970 s has out spread across the world. It is now rotating all over the world as a model, each nation builds up the model based on their choice/pattern [3]. Execution controlling is relatively everywhere for several decades in the public sector and now became an interested for public administrators, elected officials, people etc. Supervise execution is the key component for redesigning of the civil service [4].

This is the reason, [5] disagreed that the past has witness a steady gradual change in the managing of public jobs done across import market-type managerial operation in the civil service. Thus, changes now aim the enhancing eminence of performance in public jobs done, establishing fresh ways of link amid public and private service firm, and now modernized ways of accountability and regulation. Similarly, these public controlling changes have, in a difference way, been referred to the method of a state build up and economies/financial state transitional. However, there are good increases when using performance management system in the civil service. The execution management goal has a biggest-execution measure that people and groups have the authority of better business course and their methods/experience that aid within structure and make productive leadership available. So the objective of execution controlling is to build up the capacity of recruits or workers in order to improved staff execution [1]. The purpose of the result execution method is not limited to measuring outcome and executions. It's a channel and guides to policy fulfillment command and ensuring we handle that which matter most. Execution improvement in firm has become a hard matter earlier because managing/controlling propositions of theory.

Some business organization or firms in Nigeria failed due to inadequate and incompetence Performance Management method [6]. Lack of effective supervision of workers or staff. Poor appraisals of staff which contribute to under performance and productivity.

The paper presents an improved performance management system for business organization. We develop programme that can generate and keep an adequate standard of performance of workers and develop module that can give report to personnel in respect of staff performance, Hence we were able to enhance an improved system. It is a medium whereby management can monitor workers performance with aid of the accuracy of the system. This will assist business organization, company, agencies, firms and other outfits as a model to determine staff performance for decision making.

\section{RELATED WORKS}

The concept of performance management is now one of the best with useful growth in the area of human-resources management. [7], see it as a schematic and entire procedure of planning work, inspection and measuring goal for steady enhancing person and groups' worker's allowance to the attainment of firm objectives. The three illustrations now show that execution controlling has backing such as attribute and schematic. It's combined in four ways; vertically by placing business groups and person goals; basically combination, human wealth combination and combination of person goals. Execution controlling is wider than execution evaluation/assessment following focal point on the area the person carried out their work and actions which is taken by the managers or supervisor and the assistance to managed and noticed difference between standards and absolute execution 
while execution work with the procedure of the firm's job that improve the plan, progress, actualization across technological execution. Execution controlling is sometime dynamic and results oriented.

Execution is known as the accomplishment of institution in connection with its group. It involves results achieved, or achievement across sets objective of the firm. And contains results or attainment and aid by person or workers to the firm's plan objectives. [8], analyzing execution or performance as comprehensive and enclose conducts and outcomes-achieved. He stated in clear term that staff conducts will determine the results-attainment. The impact of execution has defined the duty of the mangers in three ways: Relating, Being and Doing. Relating involves communicating and visiting with managee to identify the challenges. Being the focus point on fitness of the managee's and firm execution area. [9] maintain that advised that execution staff must be judged both in privates, public, great or small organization. He called on the developing community to render job assistance, services and products. This work has over see work on some previous studies, and explained the hindrance of performance as education, experience, job contentment and salary draw back execution.

[10] pointed out in their research that impact of incentive on job is the key driver of execution of employee in Malaysia and advice others to borrow the idea to improve production in their organizations. The work showed good relationship between motivation and employee's execution or job execution.

\section{A. Approaches to High Execution}

Developing firm's work force and victory of high dedication in controlling ways of doing thing is key responsibility to management. Big execution controlling practice needs compatible awareness of the leaders. Most institutions can by themselves or outside assistance develop a right business plans hat is easy to implement.

The basic three ideas used by management to improve their firm into big reliable models of controlling. They are:

a) Developing Trust: developing trust in person is necessary and can be feasible by showing respect with dignity to people. Donating idea with people and love to them as important being will establish a feeling-of-trust-worthiness between workers in a firm.

b) Support Changes: management should support changes among the recruits by exposing them across different controlling designs.

\section{B. Execution Controllong in Business Organisation}

The first proof of the fulfillment of execution controlling method has been in the circumstance of public management that is in New York City as early as 1906. The New York Bureau of Municipal Research (NYBMR) used to gauge its firm execution on competence, outcome, and execution compute for the past and next target execution. The idea on execution measure is collection across various channels, such as workers and citizen studies, municipal statistics, and costallocating methods. Because the schedule of the size and scope of execution controlling method fulfillment has advance. Firm execution outcomes and feedback are used all over from city halls to conference meeting and from local government to federation (federal-governments) across the countries for the defense and justification of the government schemes efficacy. The acceptance of the execution controlling method has now been introduce into civil service division such as education, health, defense, tourism and so on. Execution dimension method adapted was not narrowed to the United
State, as immense majorities (79\%) of Institutional Economic Co-operation and National Progress, as well as other nation such as Slovenia, Mali, Ethiopia, and South Africa has fulfilled execution controlling procedure in order to build up good administration.

(b) McClelland's requirements of attainment Model: due to expectation of accomplishment theory/Model, it is not wrong to give the recruits or workers reports on some of their area of challenges, for it will help them to improve on their performance and production of their goal successfully.

\section{Performance Management Circle}

Execution controlling circle is a vital component in achieving firm success. The execution controlling circle depicts the levels of involvement in the procedure of organizing, supervise, analyzing and compensating worker execution.

Figure 1 is a performance management circle which explained the activities of planning, monitoring, reviewing and rewarding. All these processes are used to gauge level and target of the organization.

Planning: planning is the placing of performance assumptions and objectives for teams and person to pay awareness to their work towards attaining firm objectives.

Monitoring: is constantly evaluating of performance and providing steady report to recruits about closeness of their goal.

Reviewing: means assessing the attainments the recruits has achieved following accomplishment of their objectives.

Rewarding: is the process of rewarding recruits for good execution or performance.

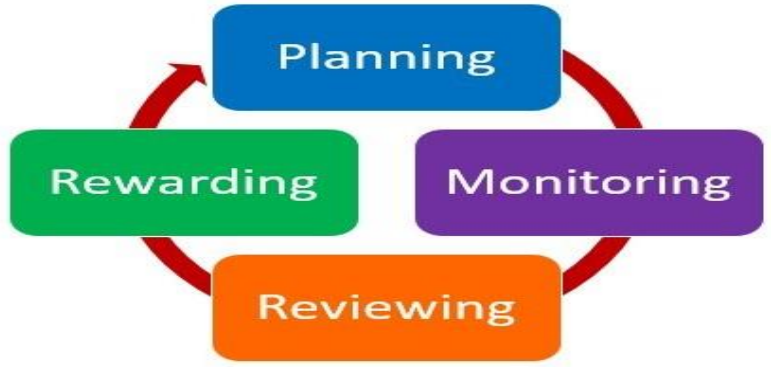

Figure1: Performance Management Circle

\section{Measurement of Performance}

Measurement of performance is described as consistent work of results and outcomes which give true information about competence of schemes.

Figure2 described measurement of performance result of the system and measured firm execution generally in three ways, they are:

a) Execution.

b) Firm Outcome.

c) Institutional grading

Peter F. Drucker is a known controlling guru, he suggested that firm's recruits have to know the link joining their performance and the results. Pointing out that staff should always see performance and production as their priority, and said before recruits may see these connections; they will work hard towards attaining big execution and management have to point out the dimension of results of execution. Performance measures is mostly used in the firm production, firm outcomes, and ranking of company/industry.

Production: can be described as total production of goods or jobs done divided by the contribution required to produce those results. Firm always targets at the output. They required the best goods and jobs done using the little contributions 
amount. Results are measure through the sales incomes a company received when goods are sold (SI x No. Sold). Contributions are judged by the amount needed to improve the resources of the firm into the results oriented. It is the organization's duty to boost results by reducing the cost of input and boost the income amount. This effort means that the performance input is competence to improve the job of the firm works. Therefore, output or results is based on the experience of the recruits how they carried out their duty. Capability of organization can only improve when staff or workers capability is improved.

Institutional productiveness: it's a judge of how suitable firm objectives look like and the way firm achieved its targets. The manager's use this to calculate performance-progress. Other explanations of firm outcomes are proposed by investigators organizers. In some cases, the method of modeling resource or institutional efficiencies suggests that result is calculated by institutional ability to improved areas that required important resources. The procedure modeling emphasized on the change procedures of the firm and how good the firm changes inputs into wanted results.

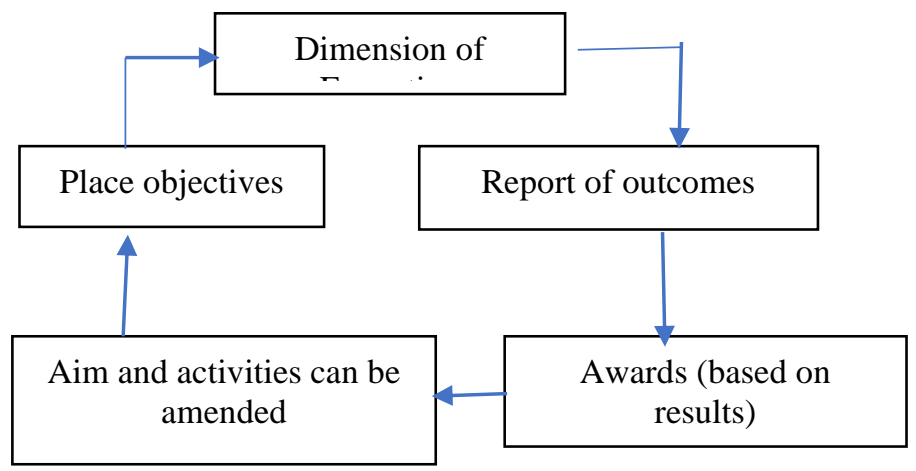

Figure2: Measurement of Performance

\section{E. Exection Enhancement Processes}

From the execution enhancement organizing procedure, comes with particular execution enhancement intervention, logics and methods. In outcome, changes and steady enhancement works are committed to operation of controlling all five-quality checkpoints. The organizing groups then advances, across the execution enhancement designing procedure, an equal attack to enhance the entire method execution, not only method sub-element. Having saved the method, calculate, obtaining and evaluate execution at the five checkpoints to discover if the assumed impacts rely take place. According to information, prepare evaluations closer to company planned, the area (internal and external), the visions plan and the enhancement action. Take note that the procedure of analyzing is split up from the procedure of dimension. In fact, dimension support enhancement as it first goal. The institutional method or study that the units are according to defied sequence to eliminates doubt. Amount of dimension and evaluations methods could be admitted here. If the firm has an outcome, big-discharge controlling procedure in the environments of designing, dimension and assessing, manage and enhancement, it shall attain its dream of subsequent and its desires results over a long term. A combined analysis point to steady enhancement is importance for these attainments.

Here are some types of execution attributes which empower Execution Controlling for robust operations and qualitative in attainment of firm objectives. They are:

a) Steady operation: Execution controlling should be a steady operation that must be handled periodically (yearly) i.e., planning staff execution and progress, supervise workers execution and monitoring managee's progress and summarized yearly production.

b) Adjustable: The Execution controlling procedure should be adjustable and make sure that the supervisor and managee acting together. Although, each of the component group should have enough manpower to plan their own procedure among the over-all structure for execution controlling.

c) Forecaster: Execution controlling should be forecast. The entire three components of execution controlling are mentored for the upcoming designing and enhancement. Evaluation method gives vital contribution to actions in feature.

d) Participation: Execution Controlling is characterized by participatory. This offers frequent understanding between the head/manager and the staff to look into execution and progress require.

e) Management: Execution Controlling goals calculate worker's total execution for calculated execution i.e., goals, levels etc.

f) Conduct of Contentment: Execution Controlling that summarized progress natures and interest herself powerful with staff emotional conduct detail and individual quality that is important process to the execution procedure. PFM identify the staff quality and conduct of each employee's level and diligently evaluate the size of their assistance to employee standard of execution. It a process of clearing the ways to recognized employee's subsequent progress need.

\section{METHODOLOGY}

The method applied here is the object oriented (OO) methodology and design. Modern procedures of performance assessment, evaluation procedure, individual assets count procedure, behaviour tie up with rating scale procedure, management by objective (CBO), psychological assessment procedure. Execution assessment is the appraisal of staff execution in which varied element are view like the outcomes of staff performance.

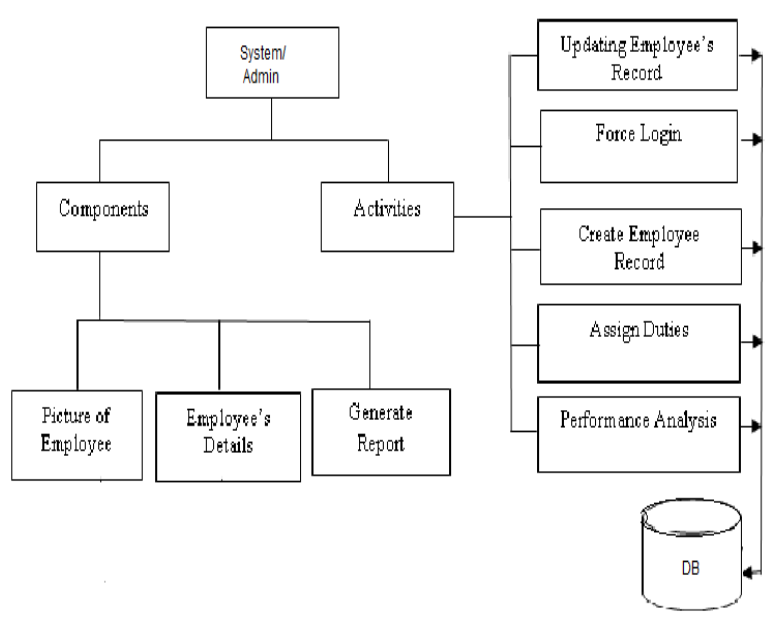

Figure3: System Architecture

Figure3, is the proposed system that comprises of two systems that is biometrics and database records table. Biometrics is used to digitally identify a person to grant access to the systems. Example, it identify fingerprint. While the database record table is used to create, update and store records of staff. 


\section{RESULTS AND DISCUSSION}

It is designed to automatically accumulate facts of each officer over a period of time, which is now analyzed performance of the staff and the performance percentage of each officer is displayed using charts and tables.

Figure4 shows the screenshot showing Pin authentication.

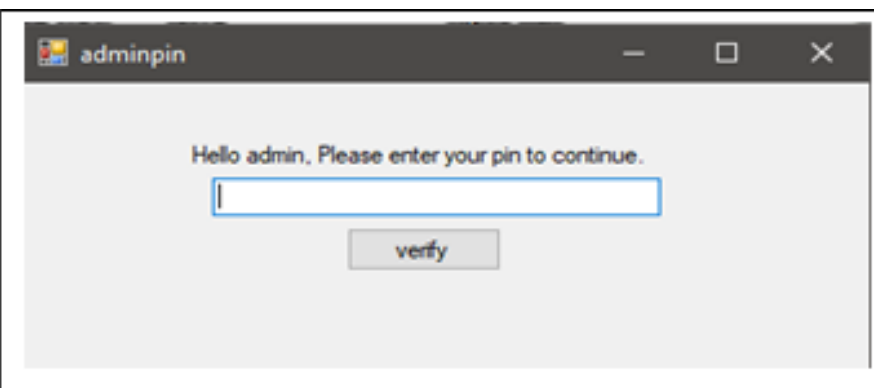

Figure4: Screenshot showing Pin authentication
Once the enrolled worker entered correct pin the dashboard page of the worker displays while the admin can login with his pin monitor workers. Figure 5 shows job skill level as been monitored by the admin.

Table1 shows the rating table. Once a task has been assigned to a worker, the level of competence exhibited by the worker while carrying out that task is been monitored. For each attribute, the admin has a rating of 1 to 5 to give the officer. 1 been the lowest and 5 the highest.
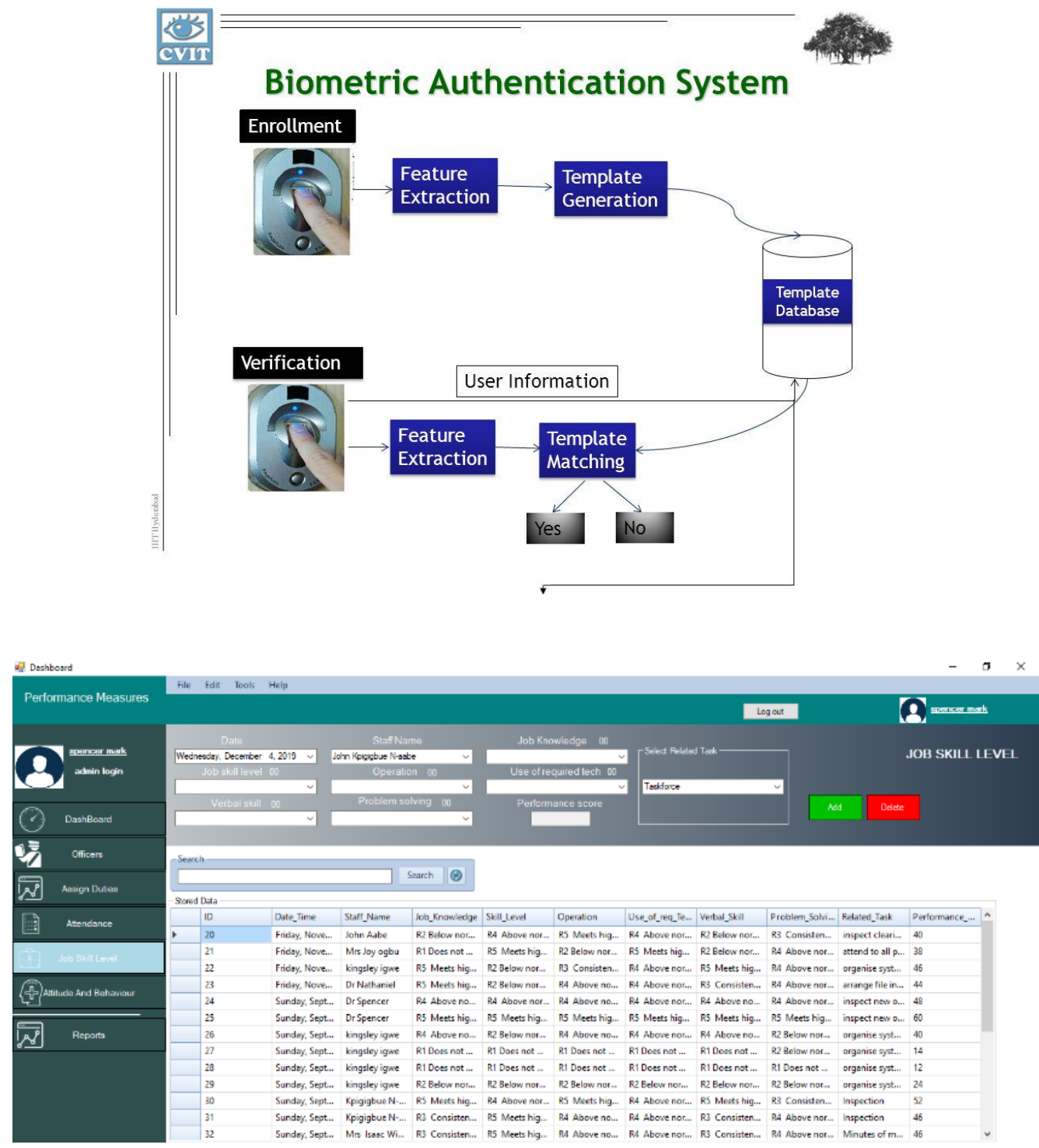

Figure5: Job Skill Level

Table1: Ratings Table

\begin{tabular}{|c|c|c|}
\hline Rating & Meaning & $\begin{array}{c}\text { Execution } \\
\text { Score }\end{array}$ \\
\hline Rating 1 & $\begin{array}{c}\text { Does not meet minimum } \\
\text { requirement }\end{array}$ & 2 \\
\hline Rating 2 & Below normal presumption & 4 \\
\hline
\end{tabular}


Table 1 shows once a task has been assigned to a worker the attitude and conduct exhibited by the worker while carrying out that duty is being monitored. For each attribute, the admin has a rating of 1 to 5 to give the officer. 1 been the lowest and 5 the highest.
Pie chart representing rating performance of assigned duty to a worker and the skill level exhibited during monitoring can also be achieved by the system. This is shown in figure 6 . Figure 7 shows the staff performance level as can be accessed by the admin.
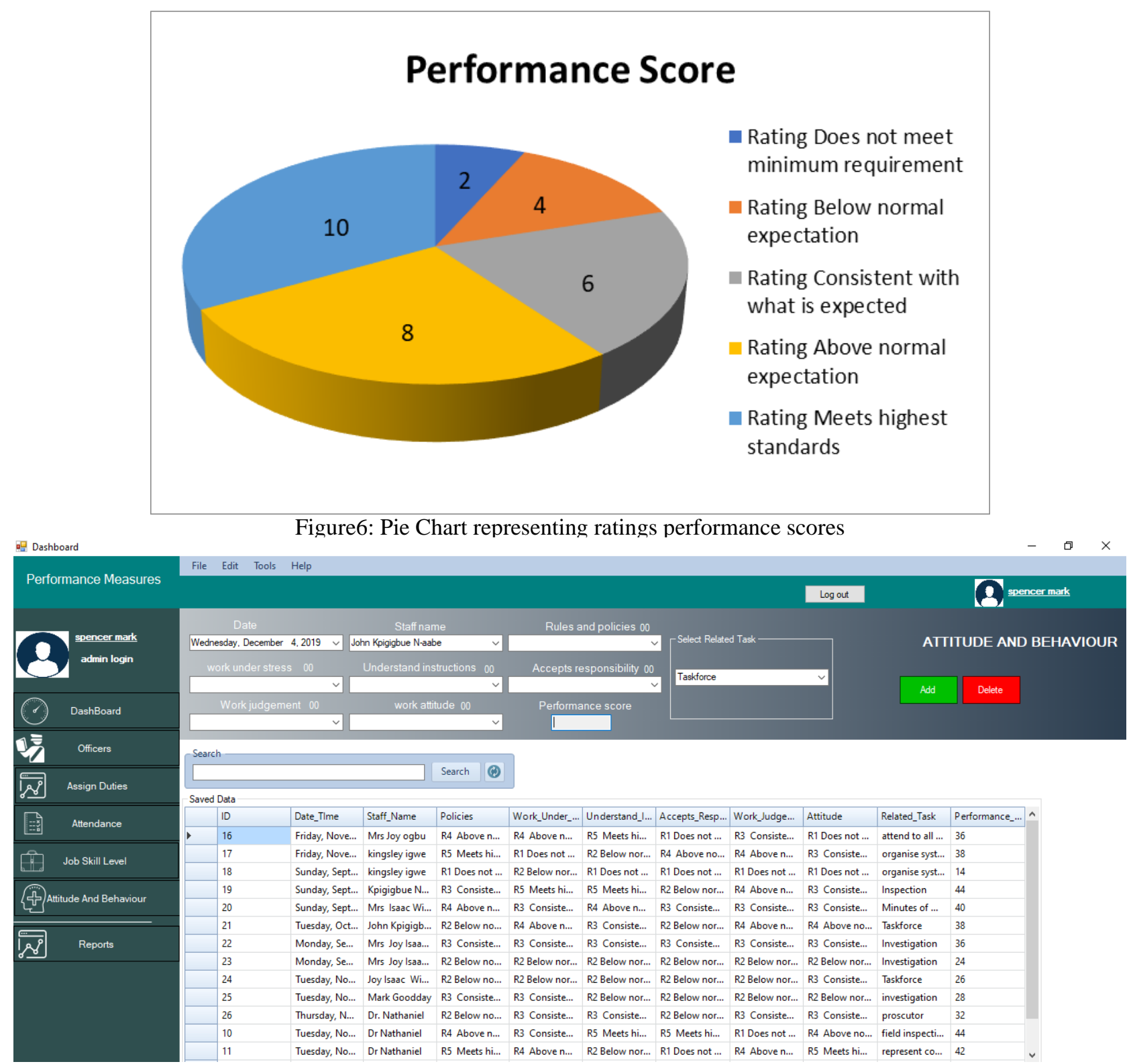

Figure7: Staff Performance level

\section{CONCLUSION}

Conclusively, the study has been designed to adopt a proposed method that is capable of assigning duties, monitoring, storing and updating information and giving feedback of any criminal acts for immediate prosecution and analyzed executions idea in the scheme that has been used. The method will be served as bases for assessment for workers promotion, compensations, rewards and awards to the best execution worker.

\section{ACKNOWLEDGMENT}

The preferred spelling of the word "acknowledgment" in America is without an "e" after the "g". Avoid the stilted expression, "One of us (R.B.G.) thanks . . ." Instead, try
"R.B.G. thanks". Put applicable sponsor acknowledgments here; DO NOT place them on the first page of your paper or as a footnote.

\section{REFERENCES}

[1] Frigo, M. L. and Kumwiede, K.R. (1999), Balanced Scored cards: A Rising Trend in Calculated; Journal of Strategic Performance Measurement, 3(5) 42-48.

[2] Pillay, P., Subban, M., \& Qwabe, B. (2008) Talent management - Putting the right people in the right jobs. Journal of Public Administration, 43(3.1), 308-323.

[3] Groot, T. and Budding, T. (2008), New Public Management's Current Issues and Future Prospects; Journal of compilation 24 (1) 9-15.

[4] Greling, D. (2016). Performance measurement in the civil service: the German experience; International Journal of 
performance and performance management 54 (7) 51 56.

[5] McCourt W. and Minogue M. (2013) Models of Public Service Reform: A Problem-Solving Approach;Special journal issue of Public Administration and Development on public management in developing countries. 4 (6) 7 - 15.

[6] Esu, I. and Inyang, I. (2009), A Case for Performance Management in the Civil service in Nigeria; International Journal of Biometric 4 (4) 98-101.

[7] Edward C. J. et al, (2013). Guidelines for the Early Controlling of Patients with Acute Ischemic Strok; internal journal of information, 34( 4) 3-4.
[8] Brumbach, G.B. (1998). Some Ideas, Issues and Predictions about performance management; Business reanalysis Article Information, 17(4) 387-402.

[9] Hatry, H. P. (2006), Performance measurement: Getting Results Textbook; Washington, D.C. Urban Institute 2nd ed. 50-57.

[10] Salleh et, al. (2013), Fairness of Performance Appraisal and Organizational Commitment; Canadian Center of Science and Education. Asian Social Science; 9(2) 121 126. 